Gynecologic and

Obstetric Investigation
Gynecol Obstet Invest 2012;73:195-200

DOI: $\underline{10.1159 / 000332396}$
Received: April 20, 2010

Accepted after revision: August 23, 2011

Published online: February 1, 2012

\title{
Does Vaginal Irrigation with Saline Solution in Women with Infectious Vaginitis Contribute to the Clinical and Microbiological Results of Antibiotic Therapy?
}

\author{
Aysel Uysal Derbent ${ }^{a}$ Mustafa Ulukanlıgil $^{b}$ Esra Aktepe Keskin ${ }^{a}$ Gül Soylu ${ }^{b}$ \\ Hasan Kafalı ${ }^{a}$ \\ Departments of ${ }^{\mathrm{a}}$ Obstetrics and Gynecology, and ${ }^{\mathrm{b}}$ Microbiology, Fatih University School of Medicine, \\ Ankara, Turkey
}

\author{
Key Words \\ Vaginitis • Vaginal irrigation · Saline solution • Candida • \\ Bacterial vaginosis
}

\begin{abstract}
Aim: To compare the clinical and microbiological results between patients with infectious vaginitis receiving vaginal irrigation with saline or no irrigation before standard antibiotic therapy. Methods: Women with vaginitis $(n=109)$ were randomized to receive vaginal irrigation with saline or no irrigation before standard antibiotic therapy. The vaginal symptoms perceived by subjects and clinical findings were assessed with a standardized scale during four follow-up visits, and Gram stain Nugent scores and vaginal fluid cultures were analyzed at each visit. Results: Vaginal discharge ( $z=$ 7.159; $p<0.001)$, pruritus ( $z=5.169 ; p<0.001)$, itching $(z=$ 2.969; $p<0.003)$ and odor scores $(z=2.303 ; p<0.021)$ were significantly reduced in the study group compared to the control group between the first visit and 3-5 days after irrigation, before the start of antibiotic therapy. The second and third visits (15 and 30-45 days after antibiotic therapy) showed that the patients' symptoms and amounts of visible vaginal discharge did not differ between the two groups.

Moreover, the microbiological cures of patients in each
\end{abstract}

\section{KARGER}

Fax +4161306 1234

E-Mail karger@karger.ch

www.karger.com
(C) 2012 S. Karger AG, Basel

$0378-7346 / 12 / 0733-0195 \$ 38.00 / 0$

Accessible online at:

www.karger.com/goi group did not differ at these visits $(z=0.447 ; p=0.655)$. Conclusion: Vaginal irrigation with saline significantly reduces self-reported symptoms in the short term but has no effect on long-term clinical and laboratory results in women with infectious vaginitis.

Copyright $\odot 2012$ S. Karger AG, Basel

\section{Introduction}

Vulvovaginal symptoms, including abnormal odor, itching, irritation, and noticeable changes in vaginal discharge, are common complaints of women who undergo gynecological examinations. Vaginal infections, including vulva-vaginal candidosis, bacterial vaginosis (BV), and trichomoniasis, are common causes of vulva-vaginal symptoms [1]. While the diagnoses of vaginal infection and detection of the responsible microorganisms require laboratory techniques and time, symptoms of vaginitis continue to bother the patient.

Preoperative vaginal preparations are used to decrease bacterial loads and prevent postoperative infections [2]. Typically, povidone-iodine (PI) is used for vaginal preparations, but it may irritate the skin. Lewis et al. [3] studied baby shampoo as an alternative to PI. They suggested that 
baby shampoo is as effective as PI in preventing postoperative infections. Studies have shown that vaginal preparations with saline solution are as effective as PI during oocyte retrieval and before vaginal surgery $[4,5]$. These findings suggest that mechanical washing is an effective method for reducing bacterial loads.

The purpose of this study was to compare clinical and microbiological results between patients with infectious vaginitis receiving vaginal irrigation with saline or no irrigation before standard antibiotic therapy.

\section{Materials and Methods}

This randomized, controlled study was performed at the Gynecology Clinic of Fatih University Hospital. The study protocol was approved by the Fatih University Institutional Review Board. Women attending the clinic who complained of vaginal discharge, itching or odor were examined by one of two gynecologists. Their gynecological and medical histories were taken. Exclusion criteria were sexual activity for less than 1 year, pregnan$\mathrm{cy}$, the presence of intrauterine devices, diabetes, chronic hepatic and renal diseases, allergic diseases and treatment for gynecological infections within the last month. Women who fulfilled the inclusion criteria were invited to participate in the study. After written informed consent was obtained, the participants were randomized to groups receiving vaginal irrigation with saline solution or no irrigation; a 1:1 randomization was used. Subjects whose microbiological analysis revealed no infection were excluded from the study (fig. 1).

Perceived vaginal symptoms (discharge, pruritus, itching, odor) were scored on a scale of $0-3(0=$ not present, $1=$ mild, $2=$ moderate, 3 = severe). A standardized speculum examination was performed, and the amount of vaginal discharge was scored. After visual inspection, vaginal swab samples were taken. Each vaginal discharge sample was collected in four swabs; two were high vaginal swabs, and two were endocervical swabs. Three swab samples were in transport media, one was stored dry, and one was put into a transport tube including saline solution. In the gynecology clinic of our department, microscopy and commercially available point-of-care tests are not available. We used clinical laboratory testing to diagnose vaginitis. Vaginal samples were transported to the laboratory in a short time and a fresh wet mount was prepared. The dry sample was used for Gram stains. Gram stains were scored using the Nugent score [6]. The reading of slides for Nugent scores was performed by the same microbiologist at the central laboratory of our hospital who was blinded to the patient groups. Neisseria gonorrhoeae, Chlamydia trachomatis, Mycoplasma species (Ureaplasma urealyticum and Mycoplasma hominis), Candida species and Trichomonas vaginalis were evaluated as vaginal pathogens. A second wet swab was inoculated on human blood agar, Thayer-Martin agar and Sabouraud dextrose agar and incubated aerobically for at least $72 \mathrm{~h}$. Following this procedure, the swab was applied to a laminated surface and mixed with saline and examined for T. vaginalis. PCR was not performed for T. vaginalis. The third swab was used for a urea-arginine LYO-2 test to analyze U. urealyticum and M. homi-

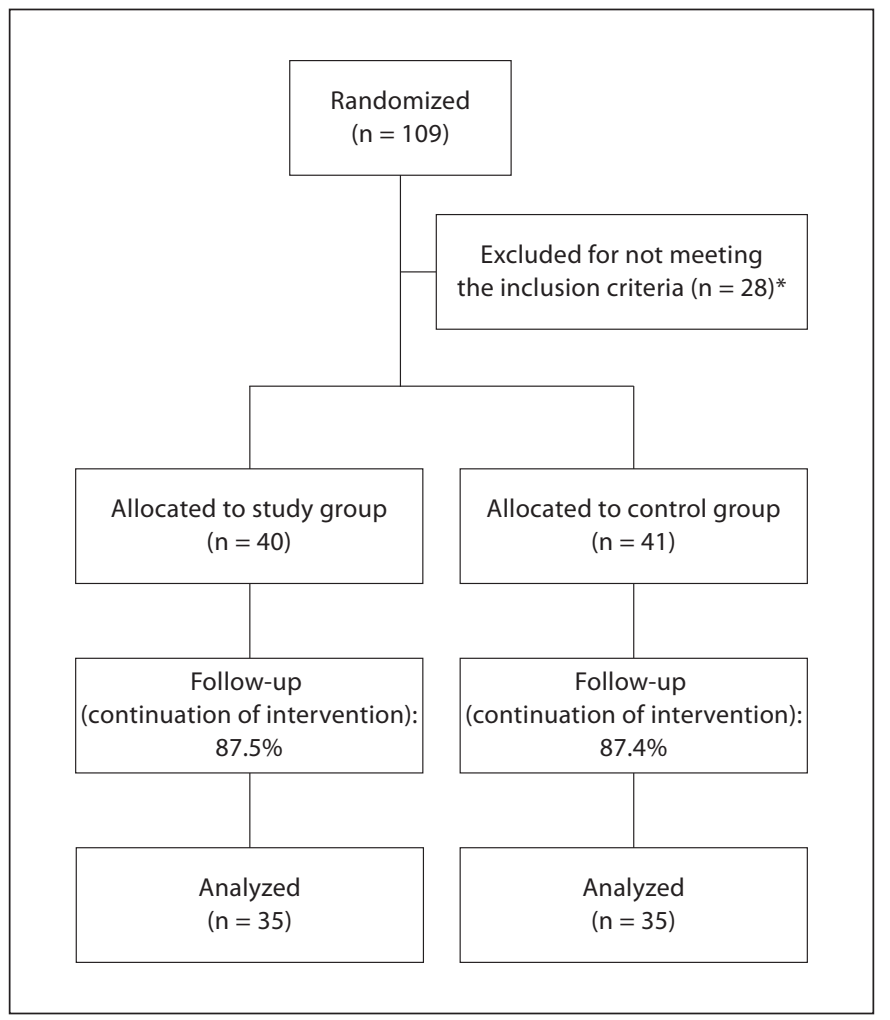

Fig. 1. Flow diagram showing the progress of participants at each stage of the study. ${ }^{*}$ Subjects whose microbiological analysis revealed no infection were excluded from the study.

nis. Finally, a C. trachomatis direct fluorescence test was performed with the fourth swab.

Diagnosis of BV was made by the relative concentration of lactobacilli, Gram-negative and Gram-positive rods, cocci (i.e. Gardnerella vaginalis, Prevotella, Porphyromonas, and peptostreptococci), and curved Gram-negative rods (i.e. Mobiluncus) on slides stained with Gram stain. Symptomatic women with $\mathrm{Nu}$ gent score $\geq 7$ were treated and included into the study. The cases with intermediate scores were only given 3 -day course intravaginal Lactobacillus capsules and excluded from the study.

If yeast, hyphea, or pseudohyphea was detected on Gramstained slides or the culture yielded a yeast species in women with vaginal discharge, Candida vaginitis was diagnosed and antifungal treatment was given. Similarly, in symptomatic cases with culture results of $U$. urealyticum or $M$. hominis, appropriate treatments were given accordingly.

\section{Study Design}

The study population was composed of 54 women. Vaginal irrigation with normal saline solution was performed and separate soaked sponges were used to irrigate the vaginal fornix. Vaginal rinsing was performed only once and not performed again at home. The control group was composed of 55 women and no vaginal irrigation was performed in this group. All women were asked to return for three additional visits within 2 months. 
Patients returned 2-5 days after the first visit to learn the laboratory test results. Women with signs of vulvar inflammation in the absence of vaginal pathogens were excluded from the study at this point. According to CDC guidelines, symptomatic patients with detectable vaginal pathogens after laboratory testing were treated to reduce symptoms, and they remained in the study. We inquired about the occurrence and severity of vaginal symptoms and whether there was any improvement in previous vaginal complaints; their answers were ranked on the same graded scale as was used at the first visit. After completing the drug therapy regimen, patients returned for a third visit (10-15 days later). The fourth visit took place 45-60 days after the first examination. At these visits, patients were asked about their vaginal symptoms with the same scale as was used previously $(0=$ not present, $1=$ mild, 2 = moderate, 3 = severe). Speculum examinations, Gram stains, wet mounts and cultures were also analyzed.

Several treatment protocols were followed. For BV, oral 500 mg metronidazole was administered (twice daily for 5 days) or intravaginal metronidazole tablets (once daily for 5 days), or intravaginal clindamycin cream $2 \%$ (once daily for 7 days). For candidosis, depending on patient preference, single dose, $150 \mathrm{mg}$ of oral fluconazole and vaginal clotrimazole or miconazole preparations were administered for 5 days. For T. vaginalis, $500 \mathrm{mg}$ metronidazole was administered (twice daily for 5 days), and partners were also treated. For C. trachomatis, $100 \mathrm{mg}$ doxycycline was administered twice daily for 7 days, or $1 \mathrm{~g}$ azithromycin was administered in a single dose [7].

\section{Outcome Measures}

The primary outcome was the assessment of the effect of vaginal irrigation on self-reported clinical symptoms and microbiological findings.

\section{Statistical Analysis}

Statistical analyses were performed using SPSS software, version 17.0 (SPSS, Chicago, Ill., USA). The power calculation used to determine the minimum sample size, assuming an $\alpha=0.05$ and $90 \%$ power, based on our pilot study in 20 patients on the proportions of clinical relief in patients with or without vaginal irrigation (0.60/0.30). A sample size of 100 was chosen as being sufficiently large to detect a $50 \%$ difference between the two groups independent of the proportions. The Shapiro-Wilk test demonstrated that none of the variables were parametric. Proportions were compared using Pearson's $\chi^{2}$ test or the Friedman test (depending on the number of related samples). A $p$ value $\leq 0.05$ was regarded as significant. When the Friedman test showed significance, we made comparisons between related pairs to explain which were different, a Wilcoxon test with Bonferroni correction was made, and $\mathrm{p}<0.016$ was regarded as significant in this case.

\section{Results}

We screened 109 symptomatic women who were examined by two gynecologists at Fatih University Hospital, Department of Obstetrics and Gynecology, between May 2009 and January 2010. The flow diagram in figure 1 shows the progress of participants at each stage of
Table 1. Baseline characteristics and findings of patients

\begin{tabular}{|c|c|c|c|}
\hline Characteristics & $\begin{array}{l}\text { Study group } \\
(\mathrm{n}=35)\end{array}$ & $\begin{array}{l}\text { Control group } \\
(\mathrm{n}=35)\end{array}$ & $\mathrm{p}$ \\
\hline Median age (IQR), years & $30.8(6.8)$ & $29.5(5.4)$ & 0.129 \\
\hline $\begin{array}{l}\text { Median coital frequency/ } \\
\text { week (IQR) }\end{array}$ & $2(1)$ & $3(1)$ & 0.404 \\
\hline $\begin{array}{l}\text { Median vaginitis/ } \\
\text { year (IQR) }\end{array}$ & $2(2)$ & $3(2)$ & 0.967 \\
\hline Candida, n (\%) & $19(53.4)$ & $16(45.7)$ & 0.473 \\
\hline Mycoplasms, n (\%) & $22(62.8)$ & $23(65.7)$ & 0.516 \\
\hline $\mathrm{BV}, \mathrm{n}(\%)$ & $11(31.4)$ & $12(34.2)$ & 0.794 \\
\hline C. trachomatis, n (\%) & $7(20)$ & $11(31.4)$ & 0.305 \\
\hline Others, n (\%) & $2(5.7)$ & $1(2.8)$ & 0.557 \\
\hline \multicolumn{4}{|c|}{ Microorganisms detected, n (\%) } \\
\hline 1 & $23(65.7)$ & $24(68.6)$ & 0.790 \\
\hline 2 & $7(20.0)$ & $7(20.0)$ & 1.000 \\
\hline$\geq 3$ & $5(14.3)$ & $4(11.4)$ & 0.720 \\
\hline
\end{tabular}

Others: Streptococcus, trichomoniasis.

the study. 39 women were excluded from the study ( 28 due to non-infectious vaginitis and 11 due to inadequate follow-up). 70 women completed all four follow-up visits. Of these, 35 comprised the study group and 35 comprised the control group.

The median patient age was 29.8 years [interquartile range $(\mathrm{IQR})=6.2$ ] in the study group and $28.4(\mathrm{IQR}=4.9)$ in the control group. There were no differences between the two groups with regard to age, reported coital frequency, number of vaginitis attacks in 1 year and microbiological etiology of vaginitis. The prevalence of detected microorganisms in the study and control groups is presented in table 1. The women's symptoms and amounts of visible vaginal discharge in the screening visit were also not different between groups.

\section{Clinical Findings in the Second Visit}

Patients returned 2-5 days after the first visit to learn the laboratory test results. Compared to the first visit, the self-reported vaginal symptoms decreased in the study group. Vaginal discharge $(\mathrm{z}=7.159 ; \mathrm{p}<0.001)$, pruritus $(\mathrm{z}=5.169 ; \mathrm{p}<0.001)$, itching $(\mathrm{z}=2.969 ; \mathrm{p}<0.003)$ and odor scores $(\mathrm{z}=2.303$; $\mathrm{p}<0.021)$ were significantly reduced in the study group compared to the control group.

\section{Findings in the Third and Fourth Visits}

After standard medical treatment, clinical and microbiological findings of patients were re-evaluated. Ta- 
Table 2. Comparison of findings from the first and second visits between groups (study and control) and comparison of findings from the first, third, and fourth visits within groups

\begin{tabular}{|c|c|c|c|c|}
\hline \multirow[t]{2}{*}{ Findings } & \multirow{2}{*}{$\begin{array}{l}\text { Com- } \\
\text { pared } \\
\text { visits }\end{array}$} & \multicolumn{2}{|c|}{ p (within groups) } & \multirow{2}{*}{$\begin{array}{l}\mathrm{p} \text { (between } \\
\text { groups); z }\end{array}$} \\
\hline & & $\begin{array}{l}\text { study } \\
\text { group }\end{array}$ & $\begin{array}{l}\text { control } \\
\text { group }\end{array}$ & \\
\hline $\begin{array}{l}\text { Discharge } \\
\text { Friedman } \\
\text { Wilcoxon* }\end{array}$ & $\begin{array}{l}1-2 \\
1-3-4 \\
1-3 \\
1-4 \\
3-4\end{array}$ & \begin{tabular}{r}
\multicolumn{1}{c}{-} \\
$<0.001$ \\
$<0.001$ \\
$<0.001$ \\
0.686
\end{tabular} & \begin{tabular}{r}
\multicolumn{1}{c}{-} \\
$<0.001$ \\
$<0.001$ \\
$<0.001$ \\
0.686
\end{tabular} & $\begin{array}{c}<0.001 \\
7.159\end{array}$ \\
\hline $\begin{array}{l}\text { Odor } \\
\text { Friedman } \\
\text { Wilcoxon* }\end{array}$ & $\begin{array}{l}1-2 \\
1-3-4 \\
1-3 \\
1-4 \\
3-4\end{array}$ & \begin{tabular}{r}
\multicolumn{1}{c}{-} \\
$<0.001$ \\
0.007 \\
0.007 \\
0.317
\end{tabular} & $\begin{array}{l}- \\
0.002 \\
0.004 \\
0.024 \\
1.000\end{array}$ & $\begin{array}{l}0.021 \\
2.303\end{array}$ \\
\hline $\begin{array}{l}\text { Pruritus } \\
\text { Friedman } \\
\text { Wilcoxon* }\end{array}$ & $\begin{array}{l}1-2 \\
1-3-4 \\
1-3 \\
1-4 \\
3-4\end{array}$ & $\begin{array}{r}- \\
<0.001 \\
<0.001 \\
0.030 \\
0.157\end{array}$ & $\begin{array}{r}- \\
<0.001 \\
0.001 \\
0.002 \\
0.059\end{array}$ & $\begin{array}{c}<0.001 \\
5.169\end{array}$ \\
\hline $\begin{array}{l}\text { Itching } \\
\text { Friedman } \\
\text { Wilcoxon* }\end{array}$ & $\begin{array}{l}1-2 \\
1-3-4 \\
1-3 \\
1-4 \\
3-4\end{array}$ & \begin{tabular}{r}
\multicolumn{1}{c}{-} \\
$<0.001$ \\
0.002 \\
0.007 \\
1.000
\end{tabular} & $\begin{array}{l}- \\
0.006 \\
0.019 \\
0.011 \\
0.180\end{array}$ & $\begin{array}{l}0.003 \\
2.969\end{array}$ \\
\hline $\begin{array}{l}\text { Number of } n \\
\text { Friedman } \\
\text { Wilcoxon* }\end{array}$ & $\begin{array}{l}\text { croorga } \\
1-3-4 \\
1-3 \\
1-4 \\
3-4\end{array}$ & $\begin{array}{l}m s \\
<0.001 \\
<0.001 \\
<0.001 \\
0.180\end{array}$ & $\begin{array}{r}<0.001 \\
<0.001 \\
<0.001 \\
0.414\end{array}$ & \\
\hline $\begin{array}{l}\text { Nugent scor } \\
\text { Friedman } \\
\text { Wilcoxon* }\end{array}$ & $\begin{array}{l}1-3-4 \\
1-3 \\
1-4 \\
3-4\end{array}$ & $\begin{array}{r}0.001 \\
<0.001 \\
<0.001 \\
0.696\end{array}$ & $\begin{array}{r}<0.001 \\
<0.001 \\
<0.001 \\
0.685\end{array}$ & \\
\hline
\end{tabular}

$1=$ First visit; 2 = second visit; 3 = third visit; 4 = fourth visit.

${ }^{*} \mathrm{p}<0.016$ is significant for comparisons of three groups.

ble 2 shows the comparison of findings in the first, third and fourth visits. In the study group, the patients' selfreported symptoms (discharge, pruritus, itching, and odor) decreased significantly from the first visit to the fourth ( $p<0.001$ for all). Nugent scores and numbers of detected microorganisms were also significantly decreased during this period ( $\mathrm{p} \leq 0.001)$. The comparison of findings from the first visit to the third demonstrated that all clinical findings, Nugent scores, and numbers of detected microorganisms were significantly reduced $(p<0.016)$. When we compared the first visit to the fourth, all findings changed in the same way except vaginal pruritus; this finding was not significantly changed between the first and fourth visits $(p>0.016)$. There were no significantly changed parameters between the third and fourth visits. Moreover, patients' microbiological cures did not differ between these visits $(\mathrm{z}=0.447$; $\mathrm{p}=0.655)$.

In the control group, all self-reported vaginal complaints, Nugent scores and numbers of detected microorganisms were decreased significantly from the first visit to the fourth. Comparison of the first and third visits showed that all symptoms, Nugent scores, and numbers of detected microorganisms were significantly reduced except itching. After medical treatment, self-reported vaginal itching did not decrease significantly in the control group ( $p>0.016)$. A comparison of the first visit to the fourth showed that all symptoms decreased significantly except vaginal odor. The amount of perceived vaginal odor did not change significantly between the first and fourth visits in the control group ( $p>0.016$ ). No parameters changed significantly between the third and fourth visits in this group. The microbiological cures between the third and fourth visits did not differ $(\mathrm{z}=1.342$; $\mathrm{p}=0.180)$.

\section{Discussion}

The results of the present study, performed in women with infectious vaginitis, showed that vaginal irrigation with saline solution before standard antibiotic therapy significantly reduced patients' self-reported symptoms. This clinical improvement facilitates the wait for the vaginal culture results, and patients can avoid taking medications during this period. All findings supported the idea that vaginal irrigation during a routine vaginal examination provides a significant reduction in patients' short-term complaints but has no effect on long-term clinical and laboratory results.

The vagina is colonized with bacteria, some of which are transient and some of which are resident. The mean bacterial counts in vaginal secretions are $10^{8}-10^{9}$ bacte$\mathrm{ria} / \mathrm{ml}$ [2]. Antiseptic douching before surgery is related to a reduction in these large numbers of bacteria. Resident organisms require antimicrobial products for their growth inhibition or elimination. Preoperative skin and vaginal preparation with an antiseptic solution to prevent postoperative infection is a routine procedure for 
many gynecological procedures [2]. Some studies suggest that the efficacy of vaginal preparations depends on mechanical washing, not the use of an antiseptic solution $[4,5]$.

The findings of our study showed that during routine vaginal speculum examinations, vaginal irrigation with saline significantly reduced patients' self-reported symptoms in the short term. These findings can be explained by the rapid decrease in the amount of vaginal discharge and bacterial loads in vaginal secretions after irrigation. However, the reduction in the number of bacteria is not sufficient for improvement. Antibiotics are necessary for eliminating pathogenic microorganisms when treating women with infectious vaginitis. To our knowledge, the findings of our study are novel. We could not find a similar study in our literature screening.

A new case-control study evaluates the efficacy of lyophilized lactobacilli in combination with $0.03 \mathrm{mg}$ estriol when compared to metronidazole in the treatment of bacterial vaginal infections (BV, aerobic vaginitis) [8]. They reported that lyophilized lactobacilli in combination with low-dose estriol are equivalent to metronidazole in the short-term treatment of bacterial vaginal infections, but have less effect after 1 month. Donders et al. [8] conclude that in symptomatic premenopausal women with disrupted vaginal flora due to bacterial vaginal infections, a physiological treatment such as Gynoflor ${ }^{\circledR}$ enables a valuable and safe alternative to therapy with an anti-infective agent like metronidazole. However, after a single treatment episode, metronidazole was more effective than exogenous lactobacilli after 1 month, indicating that a long-lasting effect with Gynoflor or other probiotics might only be obtained when applied repetitively.

Taking the findings of this and our study into consideration, we can perhaps postulate that in women with abnormal vaginal flora due to bacterial vaginal infections, vaginal irrigation and therapy with vaginal probiotics may provide more physiological treatment alternatives to therapy with antibiotics. However, future investigations are strongly required to test this hypothesis and to show the long-term efficiency of these new therapy alternatives.

The results of our study also showed that $25 \%$ of our patients had no infection. Landers et al. [9] also found no pathogenic microorganisms in $21 \%$ of symptomatic women. They concluded symptoms and physical examination signs are limited in their diagnostic power to distinguish confidently between the causes of vaginitis. A meta-analysis evaluated the role of the clinical examina- tion for the diagnosis of vaginal microorganisms. The results of that study showed the cause of vaginal complaints may be easily diagnosed when typical findings appear in microscopy [10]. The cause of vaginitis in most patients might be determined by vaginal $\mathrm{pH}$, a potassium hydroxide $(\mathrm{KOH})$ test, and microscopic examination of fresh samples of the discharge. The saline solution specimen might yield motile trichomonads or clue cells. The $\mathrm{KOH}$ specimen is used to identify the yeast or pseudohyphea of Candida species [11]. However, the absence of trichomonads or pseudohyphea does not rule out these infections. Sensitivity of microscopy is approximately $50 \%$ compared with PCR for trichomoniasis or culture for yeast. Due to shortness of time in the outpatient clinic and patient overload, we use clinical laboratory testing to diagnose vaginitis. Since laboratory techniques require approximately 2 days, empiric treatment was sometimes started based on clinical findings depending on the severity of complains. The poor performance of individual symptoms, signs, and office laboratory tests often makes it problematic to identify the cause of vaginal symptoms. In these situations, vaginal irrigation with saline may relieve patients' symptoms while laboratory procedures continue.

This study had a few limitations: (1) it was a hospitalbased study with a relatively small sample size, and (2) after a single vaginal rinsing, routine antimicrobial therapy was given to the study group so we could not demonstrate a long-lasting effect of vaginal irrigation with saline. However, according to our knowledge, it was the first randomized study investigating the effect of vaginal irrigation of patients' symptoms. This study may therefore shed light on further studies about this area.

In conclusion, in cases of infectious vaginitis, vaginal irrigation with saline significantly reduces self-reported symptoms in the short term. However, further studies with larger sample sizes are needed to determine the efficacy and effect over time of vaginal irrigation.

\section{Disclosure Statement}

The authors have no conflicts of interest to disclose. 


\section{References}

$>1$ Farage MA, Miller KW, Ledger WJ: Determining the cause of vulvovaginal symptoms. Obstet Gynecol Surv 2008;63:445-464.

2 Hager WD: Postoperative infections: prevention and management; in Rock JA, Jones HW (eds): TeLinde's Operative Gynecology. Philadelphia, Lippincott Williams \& Wilkins, 2003, vol 9, pp 195-207.

$>3$ Lewis LA, Lathi RB, Crochet P, Nezhat C: Preoperative vaginal preparation with baby shampoo compared with povidone-iodine before gynecologic procedures. J Minim Invasive Gynecol 2007;14:736-739.

-4 Van Os HC, Roozenburg BJ, Janssen-Caspers HA, Leerentveld RA, Scholtes MC, Zeilmaker GH, Alberda AT: Vaginal disinfection with povidone-iodine and the outcome of in vitro fertilization. Hum Reprod 1992;7:349350 .
Amstey MS, Jones AP: Preparation of the vagina for surgery. A comparison of povidoneiodine and saline solution. JAMA 1981;245: 39-41.

6 Nugent RP, Krohn MA, Hillier SL: Reliability of diagnosing bacterial vaginosis is improved by a standardized method of Gram stain interpretation. J Clin Microbiol 1991; 29:297-301.

7 Spence D: Vaginal discharge. BMJ 2006;332: 1155-1156.

8 Donders GG, Van Bulck B, Van de Walle P, Kaiser RR, Pohlig G, Gonser S, Graf F: Effect of lyophilized lactobacilli and $0.03 \mathrm{mg}$ estriol $\left(\right.$ Gynoflor ${ }^{\circledR}$ ) on vaginitis and vaginosis with disrupted vaginal microflora: a multicenter, randomized, single-blind, active-controlled pilot study. Gynecol Obstet Invest 2010;70: 264-272.
9 Landers DV, Wiesenfeld HC, Heine RP, Krohn MA, Hillier SL: Predictive value of the clinical diagnosis of lower genital tract infection in women. Am J Obstet Gynecol 2004; 190:1004-1010.

10 Anderson MR, Klink K, Cohrssen A: Evaluation of vaginal complaints. JAMA 2004;291: 1368-1379.

11 Sexually Transmitted Diseases Treatment Guideline 2010. Centers for Disease Control and Prevention MMWR Recomm Rep 2010;59(RR-12):1-109. http://www.cdc.gov/ mmwr/preview/. 